\title{
Genetics and medicine
}

\section{Velocardiofacial syndrome}

\author{
Alison C Pike, M Super
}

The evolution of the condition

\section{Summary}

Velocardiofacial syndrome is a syndrome of multiple anomalies that include cleft palate, cardiac defects, learning difficulties, speech disorder and characteristic facial features. It has an estimated incidence of 1 in 5000. The majority of cases have a microdeletion of chromosome 22q11.2. The phenotype of this condition shows considerable variation, not all the principal features are present in each case. Identification of the syndrome can be difficult as many of the anomalies are minor and present in the general population.

Keywords: velocardiofacial syndrome, DiGeorge anomaly, conotruncal cardiac defect

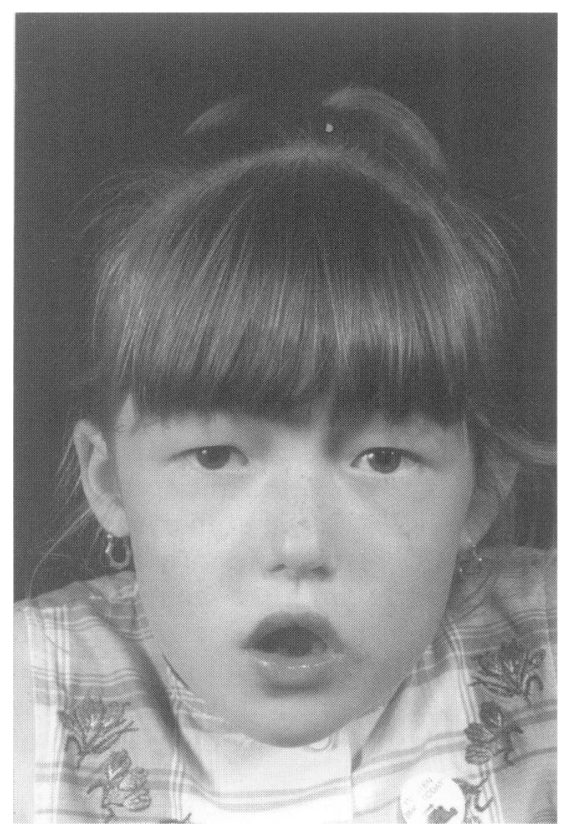

Figure 1 A seven-year-old girl with velocardiofacial syndrome

Department of Clinical Genetics, Royal Manchester Childrens' Hospital, Hospital Road, Pendlebury, Manchester, M27 4HA, UK AC Pike

M Super
In 1965 Dr Angelo DiGeorge described a child with hypoparathyroidism and recurrent infections and three necropsy cases of absent thymus and parathyroid glands at an immunological meeting and suggested that all infants with congenital hypoparathyroidism should be studied for defects in cellular immunity. ${ }^{1}$ This association became known as the 'DiGeorge syndrome'. In 1972, Dr Harold Lischner outlined the first categorisation of third and fourth branchial pouch defects defined as congenital malformation, hypoplasia or absence of the thymus and/or parathyroid glands. Additional anomalies were noted, including abnormalities of the great vessels and endocardial cushion, ear defects, micrognathia, oesophageal atresia, blunted nose and thyroid anomalies. ${ }^{2}$ The spectrum of the DiGeorge syndrome was then extended to include cardiac anomalies. ${ }^{3}$

In 1976, Kinouchi et al described the conotruncal anomaly face syndrome, with cardiac outflow tract defects, characteristic facies with hypertelorism, lateral displacement of the inner canthi, a flat nasal bridge, narrow palpebral fissures, a nasal voice and minor ear anomalies. ${ }^{4}$ Then, in 1978, Shprintzen et al described a multiple malformation syndrome including cleft palate, cardiac anomalies and a characteristic facial phenotype, called velocardiofacial syndrome (see figures 1 and 2). ${ }^{5}$

Studies on a Finnish family with a 20/22 translocation in 1981 revealed a deletion of chromosome 22 causing DiGeorge syndrome. ${ }^{6}$ It then became apparent that monosomy $22 \mathrm{q} 11$ was an important cause of DiGeorge syndrome. It was clear that there were a lot of similarities between the different conditions and once the 22q deletion had been identified in DiGeorge syndrome, patients with other conotruncal anomalies were investigated for abnormalities of this region also. ${ }^{7}$ This led to the discovery that velocardiofacial syndrome was also frequently deleted for this area, ${ }^{8}$ as is the conotruncal anomaly face syndrome. ${ }^{9}$ It is now thought that DiGeorge syndrome, velocardiofacial syndrome, and conotruncal anomaly face syndrome are part of a spectrum of phenotypic variations of the same gene defect. ${ }^{10}$ Other studies have shown that there are a wide spectrum of conditions attributable to microdeletions at chromosome 22q11, including Kousseff syndrome, Cayler syndrome, Opitz GBBB syndrome and absent pulmonary valve syndrome. DiGeorge syndrome has now become DiGeorge anomaly because of aetiological heterogeneity; the most common causes are listed in box 1 . It is best thought of not as a distinct syndrome but a developmental field defect that is causally heterogenous. Most cases of DiGeorge anomaly are sporadic, and many now feel that familial DiGeorge anomaly is actually velocardiofacial syndrome. ${ }^{11}$

Velocardiofacial syndrome is still also known as Shprintzen syndrome, and in 1993 the Newcastle upon Tyne group suggested the acronym CATCH 22, as an alternative name for the syndrome (see box 2 ). ${ }^{12}$

\section{The genetic basis of velocardiofacial syndrome}

Velocardiofacial syndrome results from a deletion of 22q11.2. Cytogenetic studies with high resolution banding will detect interstitial deletions in $20 \%$ of patients. A number of molecular markers from DNA in 22q11 have been identified and molecular studies using fluorescent in situ hybridisation (FISH) of metaphase chromosomes using cosmid probes from this region show that the majority of patients have deletions, detected in approximately $80 \%$ (figures 3 and 4) ${ }^{13,14}$ Studies have shown that the size of the deletion is variable, but it is usually large, $2-3 \mathrm{Mb}$ long, and is flanked by the markers D22S427 and D22S264. ${ }^{15,16}$ Studies aiming to define the smallest region of DNA that is commonly deleted have looked at the end points of deletions with various markers in a large number of affected patients. Results reveal that the smallest region encompasses two markers, D22S941 and D22S944, both located on a 


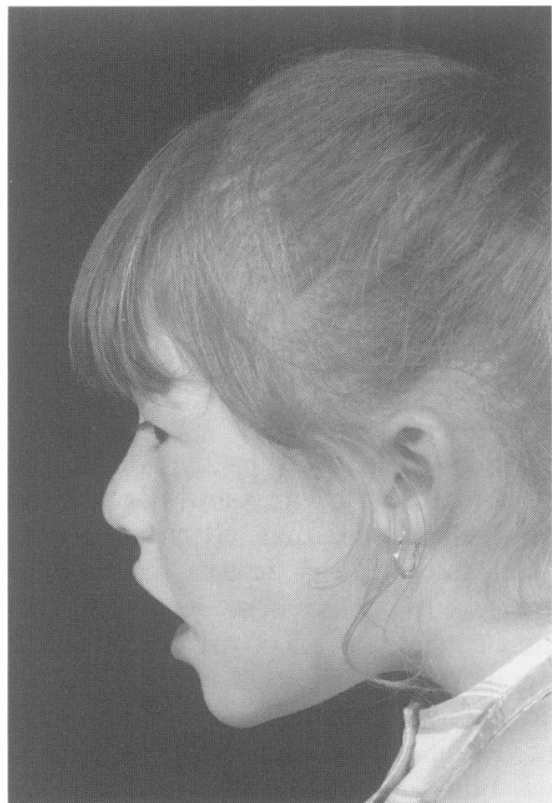

Figure 2 A seven-year-old girl with velocardiofacial syndrome

\begin{tabular}{|l|}
\hline $\begin{array}{l}\text { Causes of DiGeorge } \\
\text { syndrome }\end{array}$ \\
\hline chromosomal: $22 \mathrm{q} 11$ deletions, \\
$17 \mathrm{p} 13$ deletion, $10 \mathrm{p} 13$ deletions \\
- teratogenic: maternal alcohol, \\
maternal diabetes, retinoids
\end{tabular}

Box 1

\begin{tabular}{|ll|}
\hline CATCH & 22 acronym \\
\hline C & Cardiac anomalies \\
A & Abnormal facies \\
T & Thymic hypoplasia \\
C & Cleft palate \\
H & Hypocalcaemia \\
22 & affected chromosome \\
\hline
\end{tabular}

Box 2

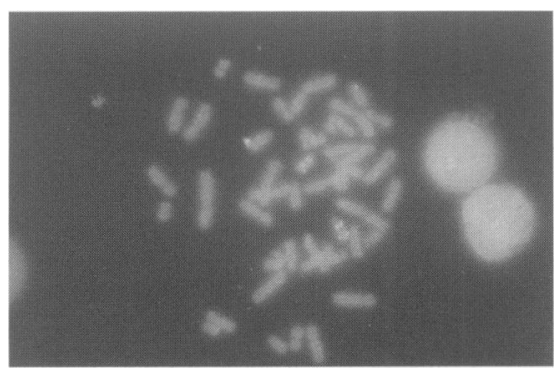

Figure 3 FISH analysis of normal metaphase chromosomes showing a signal in the control region and a signal in the probe site on each member of the chromosome 22 pair single nonchimeric YAC that is $400 \mathrm{~kb}$ long. ${ }^{17}$ The proximal deletion breakpoint maybe common amongst patients, but there are two distinct distal breakpoints. The DiGeorge critical region appears therefore to be about $500 \mathrm{~kb}$ long and is presumed to contain the major gene(s) related to the phenotype. ${ }^{18}$ The $20 \%$ of patients without a detectable deletion may have a smaller deletion within the critical region, or there may be a point mutation within the critical genes for this region, or there may be another locus for the disorder, genetic heterogeneity.

\section{VARIATIONS IN THE PHENOTYPE}

Velocardiofacial syndrome has a very wide phenotype. The principal features of the syndrome are cleft palate, cardiac anomalies, characteristic facies and learning difficulties (box 3), but many other features have also been described and are considered in more detail later. Not all the principal features are present in each case, in particular cardiac disease is not an essential feature, and is under-represented in the adult cases described to date. Identification of the syndrome can be difficult because many of the anomalies are minor and occur in the general population. ${ }^{19}$ The possible causes of this variability include changes in the size of the deletion, other modifying genetic loci, environmental or chance factors. Studies on monozygotic twins and affected members of the same family who have different clinical features indicate the enormous variability seen in the condition. Cardiac disease may be present in one member and not another; the features in one individual may be more suggestive of the DiGeorge syndrome whilst another family member may have features along the velocardiofacial spectrum. Therefore the phenotypic variability seen in this condition cannot be explained on the basis of genotypic differences alone. ${ }^{20,21}$

\section{Findings in velocardiofacial syndrome}

\section{CLEFT PALATE}

Characteristically there is a cleft of the secondary palate. This may be overt, submucous, or occult submucous. In these cases and in those without obvious clefting there is velopharyngeal insufficiency, which in turn leads to hypernasal speech. There may be discoordinate swallowing or choking and commonly in the first year of life there is a history of regurgitation of fluids down the nose. Velocardiofacial syndrome is responsible for $8 \%$ of patients with isolated cleft palate.

\section{SPEECH AND LANGUAGE DISORDER}

As already mentioned, hypernasal speech is almost invariable, and is commonly associated with delay in the onset of speech, particularly expressive speech. The hypernasality is caused by pharyngeal hypotonia, increased pharyngeal width associated with platybasia, increased distance between the pterygoid plates and adenoidal hypoplasia. This leads to problems with articulation and clarity of speech, but there are also problems with language perception in $15 \%$ of cases. ${ }^{22}$

Speech therapy before pharyngoplasty in these cases is commonly unsuccessful, but if the hypernasality is eliminated by pharyngeal flap surgery prior to the age of four years, normal speech may be achieved. An improvement in speech can be seen anytime up to four years following the pharyngoplasty but operations in infancy lead to a quicker and better response. ${ }^{23}$ Speech therapy is essential before and after surgery to eliminate compensatory articulation. At surgery, pulsations seen in the posterior pharyngeal wall in $25 \%$ are due to enlargement, tortuosity or medial displacement of the internal carotid arteries, and therefore a magnetic resonance imaging (MRI) scan is recommended in all cases prior to surgery to correctly identify the position of the carotid arteries.

\section{LEARNING DIFFICULTIES}

These are seen in most cases, and are usually moderate. Children less than six years old may lie within the normal range of intellectual and language ability but do have immature language use. They commonly have motor incoordination and poor development of numerical concepts. They do not progress beyond a concrete level of cognitive development and have poor abilities to reason abstractly, this along with persistent coordination deficits leads to increasingly poor psychological, language and academic performance with age.

\section{CARDIAC MALFORMATIONS}

These affect the conotruncal region of the heart and include a vascular ring, interrupted aortic arch, hypoplastic pulmonary arteries, Fallot's tetralogy and 


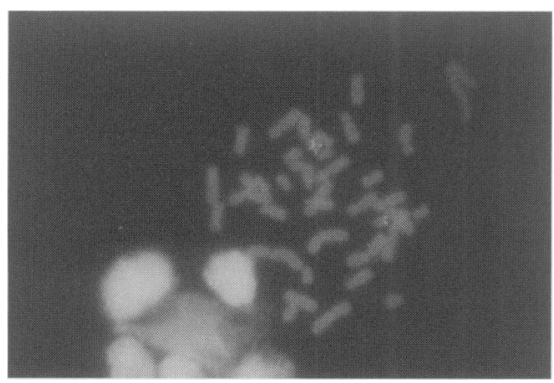

Figure 4 FISH analysis of metaphase chromosomes in velocardiofacial syndrome showing normal control signals but no signal from the probe site on one chromosome 22

\begin{tabular}{l} 
Velocardiofacial syndrome: \\
principal features \\
\hline - cleft palate \\
- cardiac anomaly \\
- abnormal facies \\
- learning difficulties
\end{tabular}

Box 3

\begin{tabular}{|l|}
\hline Velocardiofacial syndrome: \\
facial characteristics \\
\hline - myopathic \\
- broad square nasal root \\
- indentations to the side of the nose \\
- narrow alar base \\
- retrognathia \\
- short and narrow palpebral fissures \\
- promil, downturned mouth \\
\hline
\end{tabular}

Box 4

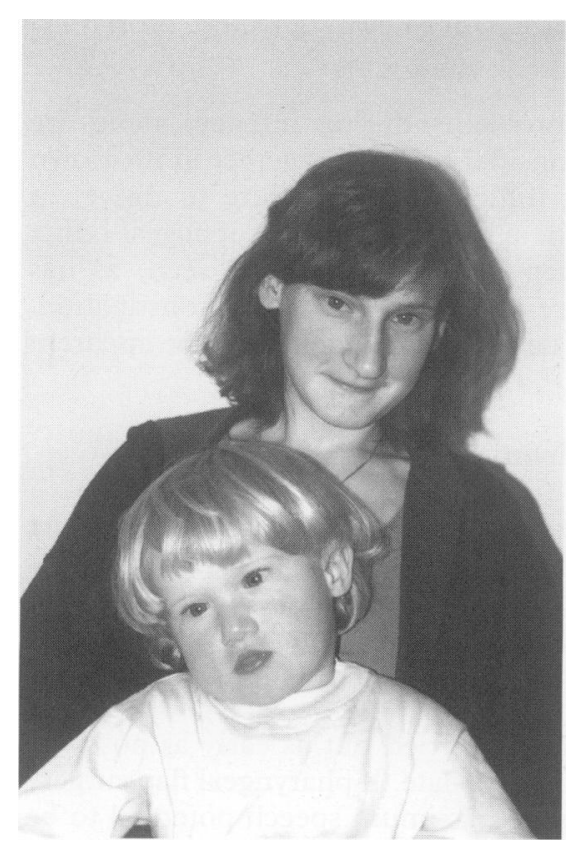

Figure 5 Velocardiofacial syndrome in a mother and son, both with a confirmed 22q11 deletion ventricular septal defect. The commonest anomalies seen are ventricular septal defect, Fallot's tetralogy and right-sided aortic arch. Cardiac lesions are found in $85 \%$ of patients with velocardiofacial syndrome and therefore all patients need cardiac assessment, even if they are asymptomatic.

Cardiac lesions are very important and may be the only finding in some patients. In fact, $3 \%$ of cases of congenital heart disease are due to a 22q11 deletion. Looking specifically at conotruncal congenital heart disease, 22q11 deletions make up 20 to $30 \%$ of all cases. Therefore a low threshold for testing for this genetic defect in congenital heart disease is necessary. ${ }^{24}$

\section{FACIAL FEATURES}

The characteristic facies are commonly described as myopathic (box 4; figures 5 and 6). There is deficiency of the malar area with vertical maxillary excess which is well demonstrated in figure 1 . The mandible is often retruded, there may be retrognathia or the Robin sequence. The Robin sequence is a secondary finding in $17 \%$ of patients with velocardiofacial syndrome. The retrognathia is related to posterior displacement of the temperomandibular joint caused by flattening of the cranial base. The mandible is not very small and relatively normal in morphology. The palpebral fissures are short and narrow, and there maybe discolouration beneath the eyes due to suborbital congestion - the allergic shiners. On fundal examination tortuous retinal vessels may be seen, there may also be congenital opacity of the margins of the cornea, or optic nerve hypoplasia. Iris nodules and cataracts have also been reported. The nasal root is broad and square, there is marked indentation either side of the nose, above the midpoint of the nostril. The alar base is narrow with deficient alae and narrow nasal openings. The ears are prominent, they may be asymmetric with an increase in anterioposterior diameter leading to a circular shaped ear. These features maybe seen in both velocardiofacial syndrome and the DiGeorge syndrome, but they more often refer to the DiGeorge syndrome. There may be minor anomalies of the ear.

The mouth is small and often open, the lips are thin with an inverted $u$ shape to the upper lip. In half the cases there is abundant scalp hair, there may also be enamel hypoplasia. ${ }^{23,25}$

\section{ENDOCRINE FEATURES}

\section{Hypocalcaemia}

Neonatal hypocalcaemia and hypoparathyroidism is well known in DiGeorge syndrome, but can also be seen in velocardiofacial syndrome. A documented history of neonatal hypocalcaemia can be found in $20 \%$ of velocardiofacial syndrome cases. The presentation is generally between birth and three months with seizures, tremor or rigidity. The hypocalcaemia is normally transient, although there has been one case described when it persisted until the age of 15 years, and three cases described where hypoparathyroidism returned in later childhood and a subsequent diagnosis of velocardiofacial syndrome was made. Therefore, severe neonatal hypocalcaemia with transient congenital hypoparathyroidism may be the earliest and only finding in infancy of the milder expression of the $22 \mathrm{q} 11$ deletion. ${ }^{26}$

\section{Hypothyroidism}

Hypothyroidism has been described in velocardiofacial syndrome, although it is a rare finding. ${ }^{25}$

\section{Short stature}

Nearly a third of patients have short stature during childhood although only $10 \%$ are below their predicted height at the end of puberty, therefore there is also a degree of constitutional growth delay.

\section{IMMUNOLOGICAL/NFECTIONS}

Thymic abnormalities are one of the hallmarks of the DiGeorge syndrome, and thymic hypoplasia or low numbers of T-cells are also seen in velocardiofacial syndrome. It is important to give irradiated blood products peri-operatively to children with cardiac lesions typical of DiGeorge syndrome unless adequate volumes of $\mathrm{T}$-cells have been documented, because of the small risk of developing graft-versus-host disease after transfusion of whole blood, plasmareduced blood and platelet transfusions containing immunocompetent cells. Frequent upper respiratory tract infections, pneumonia or bronchitis are common in velocardiofacial syndrome, as are frequent episodes of otitis media. There may be conductive or sensorineural hearing loss, and some series report conductive loss in up to $75 \%$ due to chronic otitis media. 


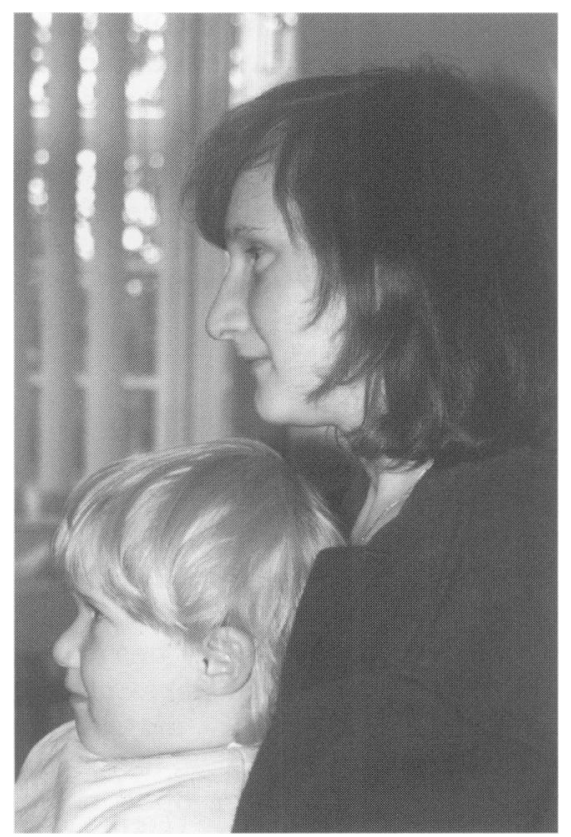

Figure 6 Velocardiofacial syndrome in a mother and son, both with a confirmed 22q11 deletion

\section{Velocardiofacial syndrome: psychiatric disorders reported}

- attention deficit disorder

- paranoid disorder

- cyclothymia

- dysthymia

- general anxiety disorder

- major depressive disorder

- schizophrenia

- manic depression

- obsessive compulsive personality disorder

\section{Box 5}

\begin{tabular}{l} 
Velocardiofacial syndrome: \\
assessment \\
\hline - echocardiography \\
- hearing test \\
- speech and language evaluation and \\
therapy \\
- palate assessment $+/-$ surgery \\
developmental follow-up $+/-$ \\
special educational needs \\
- immal ultrasound \\
- calcium check \\
- genetic testing of parents \\
genetic counselling \\
\hline
\end{tabular}

Box 6
PERSONALITY AND PSYCHIATRIC FEATURES

A typical personality has been described, patients having poor social interaction skills and a bland affect with minimal facial expression. They tend to talk in low volume voices and on a monotone level. They are described as either impulsive and disinhibited or extremely shy and serious. ${ }^{22}$ There has been a lot of recent interest in the psychiatric aspects of this disorder. ${ }^{27,28}$ Some psychiatric symptoms are quite common (box 5) and these include disturbances of mood with loss of appetite or overeating, tiredness, low self-esteem and poor concentration.

In childhood, it is common to see temper tantrums followed by remorse, older children and adults tend to show the mood disorders. It is recommended that the use of stimulants such as ritalin (methylphenidate) and dexedrine are avoided, as low levels of catechol methyltransferase (COMT) are seen in this disorder and these drugs may precipitate cycling between mania and depression. The gene for COMT lies within the deleted region, and it is postulated that hemizygosity of the COMT gene might reduce the metabolism of dopamine, noradrenaline and adrenaline, leading to psychotic illness.

\section{MUSCULOSKELETAL SYMPTOMS}

The typical slender hands and digits that may taper are seen in about $60 \%$ of this population. Other skeletal findings include scoliosis, talipes, pectus excavatum and joint laxity. It is common to see a degree of hypotonia.

\section{UROGENITAL ABNORMALITIES}

An abnormality of the urogenital system is seen in $10 \%$ of all patients. The abnormalities found include unilateral renal agenesis or hypoplasia, unilateral dilated ureter or dilated renal calyces, undescended testes or vesicoureteric reflux. Inguinal hernias are also seen.

\section{NEUROLOGICAL ABNORMALITIES}

Developmental delay has already been discussed. Hypotonia is a frequent finding, as are minor coordination defects. Seizures have been reported, and a small head circumference is a common finding. Recently, structural brain abnormalities have been described, including a small vermis, small posterior fossa, small cysts adjacent to the anterior horns and focal signal hyperintensities in white matter. No consistent pattern of structural brain abnormalities has been identified, the findings reported could be incidental, or indicate a nonspecific pattern of central nervous system dysmorphogenesis. ${ }^{29} \mathrm{~A}$ single case of holoprosencephaly ${ }^{30}$ and a case of idiopathic cerebellar and multisystem degeneration $^{31}$ have also been described.

Three patients with meningomyeloceles have been shown to have $22 \mathrm{q} 11$ deletions and as $5 \%$ of patients with neural tube defects have congenital heart disease with or without cleft palate, it is recommended that this group have chromosomal and molecular studies. ${ }^{32}$

\section{Problems in infancy}

Velocardiofacial syndrome has several problems during infancy, some are covered in other sections but it is worth considering these together in their own right. Very commonly there are feeding difficulties and failure to thrive, in patients with and without cleft palates. There maybe gastro-oesophageal reflux and nasal regurgitation of milk. Obstructive apnoea has been seen, as has oxygen desaturation without apnoea. There may be problems with constipation, and as already mentioned, hypotonia and developmental delay may be apparent in this age group.

\section{Management of velocardiofacial syndrome}

For any new diagnosis there needs to be full physical examination, including noting the dysmorphic features, and plotting growth measurements (box 6). This should also include ophthalmological examination and fundoscopy, and cardiac examination with echocardiography even if no murmur is detected. There should also be formal assessment of hearing, particularly if there is a history of repeated ear infections.

Speech and language evaluation should be carried out as early as possible, including assessment of the competency of the palate. If pharyngeal flap surgery is needed this should be performed early for maximum speech potential to be reached. It is important to carry out MRI scans prior to surgery to establish the position of the carotid arteries. Speech therapy is essential prior to and after surgery. Formal developmental assessment may be required and close 
monitoring of developmental progress is recommended so that special educational needs are identified early and additional support made available.

Other screening investigations that may be required include renal ultrasound scans looking for the $10 \%$ of patients who have renal anomalies. Thyroid function may need to be checked if there are any symptoms suggestive of hypothyroidism. Finally, in babies and young children that are diagnosed early, it is worth checking their immune function and calcium levels, but for older presentations, if there have been no symptoms, then routine testing is probably unnecessary.

Karyotype and FISH 22 analysis of the parents completes the investigations and genetic counselling should be offered to the parents as well as to the patients, at an appropriate age. These patients clearly require monitoring and this is best done with a multidisciplinary team approach.

1 DiGeorge AM. Discussions on a new concept of the cellular basis of immunology. $f$ Paediat 1965; 67: 907.

2 Lischner HW. DiGeorge syndrome. $f$ Pediatr 1972; 81: $1042-4$.

3 Conley ME, Beckwith JB, Mancer JFK, Tenckhoff $L$. The spectrum of the DiGeorge syndrome. 7 Pediatr 1979; 94: 883-90.

4 Kinouchi A, Mori K, Ando M, Takao A. Facial appearance of patients with conotruncal anomalies. Pediatr $f_{p n}$ 1976; 17: 84.

5 Shprintzen RJ, Goldberg RB, Lewin ML, et al. A new syndrome involving cleft palate, cardiac anomalies, typical facies and learning disabilities; velocardiofacial syndrome. Cleft Palate 71978 ; velocardio

6 De la Chapelle A, Herva R, Koivisto M, Aula O. A deletion in chromosome 22 can cause $\mathrm{Di}$ George syndrome. Hum Genet 1981; 57: 253-6.

7 Goldmuntz E, Driscoll D, Budarf $\mathrm{M}$, et al. Microdeletions of chromosomal region 22q11 in patients with congenital conotruncal cardiac defects. F Med Genet 1993; 30: 807-12.

8 Kelly D, Goldberg R, Wilson D, et al. Confirmation that the velocardiofacial syndrome is associated with haploinsufficiency of genes at chromosome 22q11. Am $\mathcal{F}$ Med Genet 1993; 45: chromos 12 .

9 Burn J, Takao A, Wilson D, et al. Conotruncal anomaly face syndrome is associated with a deletion within chromosome 22q11. f Med Genet 1993; 30: 822-4

10 Greenberg F. DiGeorge syndrome: an historical review of clinical and cytogenetic features $\mathcal{F} \mathrm{Med}$ Genet 1993; 30: 803-6.

11 Stevens C, Carey J, Shigeoka A. DiGeorge anomaly and velocardiofacial syndrome. Paediatrics 1990; 85: 526-30.

12 Wilson D, Burn J, Scambler P, Goodship J. DiGeorge syndrome: part of Catch 22. $7 \mathrm{Med}$ Genet 1993; 30: 852-6.
13 Driscoll D, Salvin J, Sellinger B, et al. Prevalence of 22q11 microdeletions in DiGeorge and velocardiofacial syndromes; implications for genetic counselling and prenatal diagnosis. $\mathcal{f} \mathrm{Med}$ Genet 1993; 30: 813-7.

14 Lindsay E, Goldberg R, Jurecic V, et al. Velocardiofacial syndrome: frequency and extent of 22q11 deletions. Am $\mathcal{F}$ Med Genet 1995; 57: 514-22.

15 Driscoll D. Genetic basis of DiGeorge and Velocardiofacial syndromes Curr Opin Paediatr 1994; 6: 702-6.

16 Lindsay E, Greenberg F, Shaffer L, Shapira S, Scambler P, Baldini A. Submicroscopic deletions at 22q11.2: variability of the clinical picture tions at 22q11.2: variability of the clinical picture
and delineation of a commonly deleted region. and delineation of a commonly de

17 Morrow B, Goldberg R, Carlson C, et al. Molecular definition of the 22q11 deletions in velocardiofacial syndrome. Am $\mathcal{f} \mathrm{Hum}$ Genet 1995; 56: 1391 - 403.

18 Dallapiccola B, Pizzuti A, Novelli G. How many breaks do we need to CATCH on 22q11? (Editorial) Am f Hum Genet 1996; 59: 7-11.

19 Motzkin B, Marion R, Goldberg R, Shprintzen $R$, Saenger $P$. Variable phenotypes in velocardiofacial syndrome with chromosomal deletion. fiofacial syndrome with chrom 1993; 123: 406-10.

20 Goodship J, Cross I, Scambler P, Burn J. Monozygotic twins with chromosome 22q11 deletion and discordant phenotype. $f$ Med Genet 1995; 32: 746-8.

21 Holder S, Winter R, Kamath S, Scambler P. Velocardiofacial syndrome in a mother and daughter: variability of the clinical phenotype. $\mathcal{F}$ Med Genet 1993; 30: 825-7.

22 Golding Kushner K, Weller G, Shprintzen R. Velocardiofacial syndrome: language and psychological profiles. $\mathcal{f}$ Craniofac Genet 1985; 5: $259-66$.
23 Lipson A, Yuille D, Angel M, Thompson P, Vandervoord J, Beckenham E. Velocardiofacial syndrome; an important syndrome for the dysmorphologist to recognise. $f \mathrm{Med}$ Genet 1991; 28: 596-604.

24 Young D, Shprintzen RJ, Goldberg RB. Cardiac malformations in the velocardiofacial syndrome. Am F Cardiol 1980; 46: 643-7.

25 Goldberg R, Motzkin B, Marion R, Scambler P, Shprintzen R. Velocardiofacial syndrome; a review of 120 patients. Am $\mathcal{F}$ Med Genet 1993; 45: 313-9.

26 Greig F, Paul E, Dmartino-Nardi J, Saenger P. Transient congenital hypoparathyroidism: reso-
lution and recurrence in chromosome 22q11 lution and recurrence in chromosome
deletion. $f$ Pediatrics 1996; 128: 563-7.

27 Shprintzen R, Goldberg R, Golding Kushner K, Marion $R$. Late onset psychosis in the velocardiofacial syndrome (letter) $A m \mathcal{F}$ Med Genet 1992; 42: 141-2.

28 Chow E, Bassett A, Weksberg R. Velocardiofacial syndrome and psychotic disorders: implications for psychiatric genetics. Am 7 Med Genet 1994; 54: $107-12$.

29 Mitnick R, Bellow J, Shprintzen R. Brain anomalies in velocardiofacial syndrome. $A m \mathcal{F}$ Med Genet 1994; 54: 100-6.

30 Wraith J, Super M, Watson GH, Phillips M. Wraith J, Super M, Watson GH, Phillips $M$. Velocardiofacial syndrome presenting as holo-
prosencephaly. Clin Genet 1985; 27: 408-10.

31 Lynch D, McDonald-McGinn D, Zachai E, et al. Cerebellar atrophy in a patient with velocardiofacial syndrome. $\mathcal{F}$ Med Genet 1995; 32: 561 3.

32 Nickel RE, Pillers DA, Merkens $M$, et al. Velocardiofacial syndrome and DiGeorge sequence with meningomyelocele and deletions of the 22q11 region. Am F Med Genet 1994; 52: $445-9$. 